\title{
Life-long Maternal Cafeteria Diet Promotes Tissue-Specific Morphological Changes in Male Offspring Adult Rats
}

\author{
CAROLYNE D.S. SANTOS ${ }^{1}$, SANDRA L. BALBO ${ }^{1}$, ANA T.B. GUIMARÃES ${ }^{1}$, \\ SARA C. SAGAE ${ }^{1}$, FÁBIO NEGRETTI ${ }^{2}$ and SABRINA GRASSIOLLI ${ }^{1}$
}

\begin{abstract}
${ }^{1}$ Laboratório de Fisiologia Endócrina e Metabolismo/LAFEM, Centro de Ciências Biológicas e da Saúde/CCBS, Universidade Estadual do Oeste do Paraná/UNIOESTE, Rua Universitária, 2069, Jardim Universitário, 85819-110 Cascavel, PR, Brazil ${ }^{2}$ Laboratório de Fisiologia Endócrina e Metabolismo/LAFEM, Centro de Ciências Médicas e Farmacêuticas/CCMF, Universidade Estadual do Oeste do Paraná/UNIOESTE, Rua Universitária, 2069, Jardim Universitário, 85819-110 Cascavel, PR, Brazil
\end{abstract}

Manuscript received on May 9, 2017; accepted for publication on August 29, 2017

\begin{abstract}
Here, we evaluated whether the exposure of rats to a cafeteria diet pre- and/or post-weaning, alters histological characteristics in the White Adipose Tissue (WAT), Brown Adipose Tissue (BAT), and liver of adult male offspring. Female Wistar rats were divided into Control (CTL; fed on standard rodent chow) and Cafeteria (CAF; fed with the cafeteria diet throughout life, including pregnancy and lactation). After birth, only male offspring (F1) were maintained and received the CTL or CAF diets; originating four

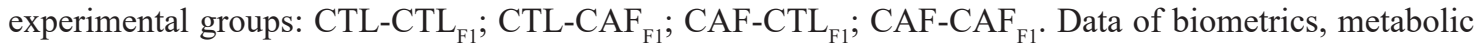
parameters, liver, BAT and WAT histology were assessed and integrated using the Principal Component Analysis (PCA). According to PCA analysis worse metabolic and biometric characteristics in adulthood are associated with the post-weaning CAF diet compared to pre and post weaning CAF diet. Thus, the CTL-CAF $F_{\mathrm{F} 1}$ group showed obesity, higher deposition of fat in the liver and BAT and high fasting plasma levels of glucose, triglycerides and cholesterol. Interestingly, the association between pre and post-weaning CAF diet attenuated the obesity and improved the plasma levels of glucose and triglycerides compared to CTL-CAF $F_{\mathrm{F} 1}$ without avoiding the higher lipid accumulation in BAT and in liver, suggesting that the impact of maternal CAF diet is tissue-specific.
\end{abstract}

Key words: obesity, dams, offspring, histology.

\section{INTRODUCTION}

Maternal over nutrition during pregnancy and lactation increases the risk of obesity, Metabolic Syndrome (MS) and Type 2 Diabetes (T2D) in the offspring during adulthood (Smith and Ryckman 2015). These early effects of the nutritional

Correspondence to: Sandra Lucinei Balbo

E-mail: slbalbo@hotmail.com maternal environment on the growth and metabolism of offspring and their long-term impact on health are defined as metabolic programming (Desai et al. 2015, Sedaghat et al. 2015, Smith and Ryckman 2015); a concept previously established by Barker and colleagues. These authors showed that an adverse fetal environment, followed by an obesogenic diet in postnatal life, may lead to chronic disease in adulthood (Barker 2004). 
Moreover, post-weaning exposure to hypercaloric diet induces the development of obesity, disruption in glucose-insulin homeostasis, dyslipidemia, liver steatosis, and cardiovascular diseases (King et al. 2014, Mucellini et al. 2014, Li et al. 2015). As such, experimental obesity can be produced by maternal or post-weaning dietary manipulations. The cafeteria diet (CAF) is a reliable model of dietary obesity in humans, promoting voluntary hyperphagia, body weight gain, exacerbated adipose tissue expansion, hyperglycemia and hyperinsulinemia, and inflammatory processes in the liver and adipose tissue (Sampey et al. 2011, Mucellini et al. 2014). Similarly, maternal exposure to CAF diet during gestation and lactation induces higher body weight gain and adipose tissue content as well as metabolic abnormalities, such as hypercholesterolemia, hyperinsulinemia and hyperleptinemia in dams (Mucellini et al. 2014). Maternal obesity can induce the metabolic programming of offspring in adulthood, culminating in obesity and its associated metabolic disorders (Howie et al. 2009, White et al. 2009, Li et al. 2011, Daniel et al. 2014, Jacobs et al. 2014). The epigenetic molecular mechanisms, specifically DNA methylation, explain the relationship between maternal obesity induced by CAF diet and metabolic programming of offspring in adulthood (Masuyama and Hiramatsu 2012). Therefore, maternal weight during pregnancy is altered methylation patterns in the child's DNA and later infant adiposity (Dunford and Sangster 2017). Thus, the maternal nutritional state by epigenetic mechanism determines which genes are expressed can enable the developing fetus to adapt to its environment at birth (Masuyama and Hiramatsu 2012, Dunford and Sangster 2017). In addition, the programmed metabolic phenotype, found in the offspring, could be exacerbated during growth, in particular when offspring are also exposed to a life-long obesogenic diet (Mucellini et al. 2014). However, while the effects of maternal over nutrition on weight gain and metabolism in offspring, before weaning, are well characterized (Smith and Ryckman 2015, Sedaghat et al. 2015), their persistent effects on adipose tissue content, glucose tolerance, insulin resistance and liver abnormalities in adulthood are contradictory (Tamashiro et al. 2009, Akyol et al. 2012, King et al. 2014, Mucellini et al. 2014). Thus, understanding how pre- and post-natal environment interactions affect the growth and development of offspring is fundamental, since the timing of an insult determines which organ or systems will be altered, when obesity occurs and the severity of diseases, later in life (Lukaszewski et al. 2013, Lee 2015, Ramírez-Lopes et al. 2015). As such, some tissues appear to be more vulnerable to nutritional insults during development. Thus, marked programming effects have been observed in White Adipose Tissue (WAT), Brown Adipose Tissue (BAT) and liver (Bringhenti et al. 2015, Kayser et al. 2015). Surprisingly, it was recently shown that maternal over nutrition could protect against the deleterious effects of the obesogenic diet during adulthood (Mucellini et al. 2014). In the present study, we evaluated whether the exposure to a CAF diet, preand post-weaning (alone or combined), modifies the histological characteristics of the WAT, BAT and liver of adult male offspring.

\section{MATERIALS AND METHODS}

\section{EXPERIMENTAL METHODS}

The Committee onEthicsinAnimalExperimentation of the State University of Western Parana approved all experiments (CEUA-10/12/2013). All animals used in this study were housed under controlled room temperature $\left(21 \pm 2^{\circ} \mathrm{C}\right)$, light $(12 \mathrm{~h}$ light/dark cycle), and had free access to food and water. At 21 days of age, 16 Wistar female rats were randomly divided into two dietary experimental groups: (1) Control group (CTL), fed on standard rodent chow (12.39 kJ/g — NuvilabTM, Colombo, Brazil) and water ad libitum; and (2) Cafeteria group (CAF), 
fed on a cafeteria diet. The CAF diet compositions as well as, the form as CAF diet was offered were adapted from previous studies (Reeves 1997, Goularte et al. 2012, Mucellini et al. 2014). Briefly, the amounts of foods were provided in excess and changed daily, avoiding that animals received the same foods and subsequent days. In addition, soft drink was provided daily. Detailed information about the nutritional value and ingredients of all foods used in this model has been previously published (Goularte et al. 2012, Mucellini et al. 2014).

At $70 \mathrm{~d}$ of age, CTL $(\mathrm{n}=8)$ and CAF $(\mathrm{n}=8)$ female rats were mated with a control male $(n=8)$ in a harem system (ratio of 2 females to 1 male) during approximately two weeks. In this age female rats that consumed CAF diet were obese compared to CTL female, according previous results published by Sagae et al (2015). The pregnant females were housed in individual cages until delivery.To maximize lactation performance, after birth, the litter size was adjusted to eight pups per dam. Only male offspring were studied; when the number of male rats was insufficient, females were maintained during lactation phase to complete the number of animals in each litter. After weaning (21 days), these male offspring (F1) were fed with CTL or CAF diets for 11 weeks and were allocated to the groups:

- CTL-CTL ${ }_{\mathrm{F} 1}$, control offspring born from dams that were fed on control diet;

- CTL-CAF ${ }_{\mathrm{Fl}}$, cafeteria offspring born from dams that were fed on control diet;

- CAF-CTL $\mathrm{F}_{1}$, control offspring born from dams that were fed on a cafeteria diet;

- CAF-CAF ${ }_{\mathrm{F} 1}$, cafeteria offspring born from dams that were fed on a cafeteria diet.

Importantly, in all experimental groups the number of animals analyzed was 5-7 rats per group from five different litters.
BODY WEIGHT, ADIPOSE TISSUE CONTENT AND PLASMA METABOLIC PARAMETERS

At $100 \mathrm{~d}$ of age, after $8 \mathrm{~h}$ of fasting, the body weight (bw) of adult F1 offspring was evaluated. Rats were submitted to euthanasia and total blood was collected and the plasma separated by centrifugation. The concentrations of total cholesterol, triglycerides and glucose were quantified by colorimetric and enzymatic commercial kits (LaborLab). The retroperitoneal fat depot was removed, weighed and values expressed as $\mathrm{g} / 100 \mathrm{~g}$ of bw. This fat depot was used as representative of WAT for histological analysis. Brown Adipose Tissue (BAT) and liver were also removed and weighed for histological analysis.

\section{HISTOLOGICAL ANALYSIS}

The WAT was cut in 2 portions of $0.5 \mathrm{~cm}$ in diameter and $0.5 \mathrm{~cm}$ thick with the aid of a mold. The liver was sectioned into 3 parts by transverse cuts in its major axis. The BAT was sectioned into 2 parts with cross sections in its major axis. Briefly, dissected tissues were fixed in 10\% neutral buffered formalin (Merck, Buenos Aires, Argentina) for $72 \mathrm{~h}$. Dehydration was performed by passing the samples through ethanol solutions of increasing graduation (70, 80, 90 and 100\%), diafanization in xylol and final embedding in paraffin. The tissues were cut into 5- $\mu \mathrm{m}$ sections on a Reichert Jung rotary microtome (Leica RM 2025 Microsystems Inc., Wetzlar, Germany) and Hematoxilin and Eosin (H\&E) were used for staining. The slides were photographed using a light microscope (Olympus BX 50), coupled to a digital camera (SAMSUNG SHC-410NAD) using photo Micro 5.6 software. Sections were photographed along their entire length, field to field and the images captured were analyzed using the Image J $1.48 \mathrm{v}$ program, which was previously calibrated to $100 x$ and $200 x$ and standardized for the analysis of each image (Corel 
Draw X7 program). All analyzes were performed by a single observer.

Histological measurements were carried out for each tissue evaluated. Posterior the WAT was photographed at a magnification $100 \mathrm{x}$ and the number of adipocyte was performed field to field. Additionally, all adipocytes in all the sections were circled and the adipocyte area $\left(\mathrm{mm}^{2}\right)$ was measured. For the BAT images were photographed at 200x magnification and cell proliferation evaluated by the adipocyte nuclei count (3 sections/slide). Qualitative analysis of the BAT depot was also performed to assess the size of fat droplets in the adipocyte cytoplasm using the following criteria: smaller droplets $(+)$, median droplets $(++)$ and larger droplets $(+++)$. Using a default template $(0.5$ $\mathrm{cm})$ the areas of hepatic tissue were selected and photographed at a magnification 100x and images were used for qualitative analysis of the presence of infiltrated fat in the hepatocyte cytosol. For this analysis, at least 20 photos were assessed by a single observer. The magnitude of steatosis was evaluated by Brunt's classification (Brunt 2001) with modifications for rodent models. Briefly, steatosis was graded ( $0-3)$, as follows: 0 , none to $5 \%$ of hepatocytes affected; $1,>5 \%$ to $30 \%$ affected; $2,>30 \%$ to $60 \%$ affected; and $3,>60 \%$ affected. The qualitative hepatic and BAT histopathology were statically analyzed by permutacional Monte Carlo test followed adjusted residuals test.

\section{STATISTICAL ANALYSIS}

The body weight, weight of the retroperitoneal fat depot, triglycerides, cholesterol and glucose were assessed for normality by Shapiro-Wilk test and homoscedasticity by the Levene test. The variables were compared by two-way ANOVA, maternal $\operatorname{diet}(\mathrm{CTL}$ and $\mathrm{CAF})$ and offspring $\operatorname{diet}\left(\mathrm{CTL}_{\mathrm{F} 1}\right.$ and $\left.\mathrm{CAF}_{\mathrm{F} 1}\right)$ as factors to evaluate the effects of isolated factors and their interaction ( $F$ values) on the metabolic state of offspring. The Tukey-HSD post- hoc test used. Associations of biometric, metabolic plasma parameters and histological variables with maternal and offspring diet was made by Principal Components Analysis (PCA) (Hair et al. 2009). Univariate analyses were performed using the Prism 6.0 software (GraphPad Prism version 6.05 for Windows; GraphPad Software, La Jolla, CA, USA) and multivariate analyses were performed using the Paleontological statistics software package for education and data analysis (Past); (Hammer et al. 2001). Differences were considered as significant when $\mathrm{p}<0.05$.

\section{RESULTS}

The body weight of offspring at $100 \mathrm{~d}$ of age was affected by the offspring diet $\left(\mathrm{F}_{1.18}=61.11\right.$; $\mathrm{p}<0.0001)$, by the maternal diet $\left(\mathrm{F}_{1.18}=5.86\right.$; $p=0.026)$, and by the interaction between the offspring and maternal exposures $\left(\mathrm{F}_{1.18}=7.423\right.$; $\mathrm{p}=0.014)$. Thus, adult $\mathrm{F} 1$ offspring in the CTL$\mathrm{CAF}_{\mathrm{F} 1}$ and $\mathrm{CAF}-\mathrm{CAF}_{\mathrm{F} 1}$ groups presented higher body weights than the animals of the CTL-

$\mathrm{CTL}_{\mathrm{F} 1}$ and $\mathrm{CAF}-\mathrm{CTL}_{\mathrm{F} 1}$ groups. Neither maternal nor offspring diets affected significantly the weight of BAT in adult offspring at $100 \mathrm{~d}$ of age. However, the weight of liver of offspring at $100 \mathrm{~d}$ of age was affected by offspring diet $\left(\mathrm{F}_{1.19}=5.253 ; \mathrm{p}=0.0335\right)$ and by interaction between the offspring and maternal exposures $\left(\mathrm{F}_{1.19}=5.435 ; \mathrm{p}=0.0309\right)$. The factor maternal diet did not affect this parameter $\left(\mathrm{F}_{1.19}=0.03174 ; \mathrm{p}=0.8605\right)$. Thus, the CAF diet consumption post weaning $\left(\mathrm{CTL}-\mathrm{CAF}_{\mathrm{F} 1}\right)$ result in increased liver weight in relation to $\mathrm{CTL}-\mathrm{CTL}_{\mathrm{F} 1}$. Retroperitoneal fat depot weight was influenced only by the offspring $\operatorname{diet}\left(\mathrm{F}_{1.18}=15.77 ; \mathrm{p}=0.0009\right)$. Thus, adult $\mathrm{F} 1$ offspring in $\mathrm{CTL}-\mathrm{CAF}_{\mathrm{F} 1}$ group presented higher retroperitoneal content compared with of those of the CTL-CTL ${ }_{\mathrm{F} 1}$.

The plasma levels of triglycerides, total cholesterol, and glucose were independently affected by offspring diet $\left(\mathrm{F}_{1.17}=16.87 ; \mathrm{p}=0.0007\right.$; 
$\mathrm{F}_{1.18}=21.11 ; \mathrm{p}=0.0002 ; \mathrm{F}_{1.18}=19.99, \mathrm{p}=0.0003$, respectively) and maternal diet $\left(\mathrm{F}_{1.17}=10.66\right.$; $\mathrm{p}=0.004 ; \mathrm{F}_{1.18}=5.84 ; \mathrm{p}=0.02 ; \mathrm{F}_{1.18}=4.94, \mathrm{p}=0.039$; respectively). No interactions between maternal and offspring diets were observed, as shown in Table I. Thus, the concentration of triglycerides in plasma was significantly higher in CTL-CAF ${ }_{\mathrm{F} 1}$, compared with others groups $(\mathrm{p}<0.05)$. In addition, at $100 \mathrm{~d}$ of age, the adult CTL-CAF ${ }_{\mathrm{F} 1}$ and CAF$\mathrm{CAF}_{\mathrm{F} 1}$ groups displayed hypercholesterolaemia and hyperglycemia, compared with CTL-CTL $\mathrm{F}_{1}$. Adult F1 offspring in the CTL-CAF ${ }_{\mathrm{F} 1}$ group presented lower numbers of adipocytes and larger individual adipocyte sizes, in the retroperitoneal fat depot, when compared with adipocyte of the CTL-CTL ${ }_{\mathrm{F} 1}$ rats $(\mathrm{p}<0.05)$. Both adipocyte numbers $\left(\mathrm{F}_{1.17}=7.76 ; \mathrm{p}=0.01 ;\right.$ Figure $\left.1 \mathrm{e}\right)$ and adipocyte size $\left(\mathrm{F}_{1.17}=6.59 ; \mathrm{p}=0.02\right.$; Figure $\left.1 \mathrm{f}\right)$ were affected only by post weaning exposure to CAF diet. Neither maternal nor post weaning exposure to the CAF diet altered inflammatory processes in the retroperitoneal fat depot (data not shown). The histological analyses of BAT are shown in Figure 2a-e. Cell proliferation in BAT was analyzed quantitatively by counting nuclei, revealing no significant difference between groups. The number of nucleus count in BAT was not affected neither by maternal diet $\left(\mathrm{F}_{1.0}=0.022 ; \mathrm{p}=0.89\right)$ nor by interactions $\left(\mathrm{F}_{1.18}=0.67 ; \mathrm{p}=0.42\right)$ (Figure $\left.2 \mathrm{e}\right)$, but was affected by offspring diet $\left(\mathrm{F}_{1.0}=5.71 ; \mathrm{p}=0.03\right)$. Qualitative analysis demonstrated that only adult F1 offspring exposed to the CAF diet post weaning induced lipid accumulation in BAT. Thus, increased lipid droplet contend were found in BAT from adult F1 offspring of the CTL-CAF ${ }_{F 1}$ and CAF-CAF ${ }_{F 1}$ groups, compared with those of the CTL-CTL ${ }_{\mathrm{F} 1}$ and $\mathrm{CAF}-\mathrm{CTL}_{\mathrm{F} 1}$ groups. Confirming the qualitative descriptive analysis, higher presence of lipid median droplets were found in BAT from adult $\mathrm{F} 1$ offspring of CTL-CAF ${ }_{\mathrm{F} 1}$ and $\mathrm{CAF}-=\mathrm{CAF}_{\mathrm{F} 1}$ groups

TABLE I

Body weight, weight of the liver, WAT and BAT, triglycerides, total cholesterol and plasma glucose concentrations in male adult $\mathrm{F} 1 \mathrm{offspring}$ aged $100 \mathrm{~d}$.

\begin{tabular}{|c|c|c|c|c|c|c|c|}
\hline & CTL-CTL $_{\mathrm{F} 1}$ & CTL-CAF ${ }_{\mathrm{F} 1}$ & $\mathrm{CAF}-\mathrm{CTL}_{\mathrm{F} 1}$ & CAF-CAF ${ }_{\mathrm{F} 1}$ & $\begin{array}{l}\text { p-value } \\
\text { mother }\end{array}$ & $\begin{array}{l}\text { p-value } \\
\text { offspring }\end{array}$ & $\begin{array}{c}\mathrm{p} \text {-value } \\
\text { interaction }\end{array}$ \\
\hline $\begin{array}{c}\text { Body weight } \\
\text { (g) }\end{array}$ & $211.2 \pm 4.0^{\mathrm{b}, \mathrm{d}}$ & $256.4 \pm 4.99^{\mathrm{a}, \mathrm{c}, \mathrm{d}}$ & $212.5 \pm 3.76^{\mathrm{b}, \mathrm{d}}$ & $234.3 \pm 4.32^{\mathrm{a}, \mathrm{b}, \mathrm{c}}$ & 0.026 & $<0.0001$ & 0.014 \\
\hline $\begin{array}{l}\text { WAT weight } \\
(\mathrm{g} / 100 \mathrm{~g})\end{array}$ & $1.0 \pm 0.29^{\mathrm{b}}$ & $1.9 \pm 0.11^{\mathrm{a}, \mathrm{c}}$ & $0.9 \pm 0.10^{\mathrm{b}}$ & $1.6 \pm 0.21$ & 0.299 & 0.0009 & 0.580 \\
\hline $\begin{array}{l}\text { Liver weight } \\
\qquad(\mathrm{g} / 100 \mathrm{~g})\end{array}$ & $3.25 \pm 0.19^{b}$ & $3.87 \pm 0.05^{\mathrm{a}}$ & $3.59 \pm 0.10$ & $3.58 \pm 0.12$ & 0.860 & 0.033 & 0.030 \\
\hline $\begin{array}{l}\text { BAT weight } \\
(\mathrm{g} / 100 \mathrm{~g})\end{array}$ & $0.25 \pm 0.08$ & $0.19 \pm 0.02$ & $0.21 \pm 0.02$ & $0.29 \pm 0.03$ & 0.574 & 0.806 & 0.151 \\
\hline $\begin{array}{l}\text { Triglycerides } \\
\text { (mg/dL) }\end{array}$ & $181.0 \pm 25.9^{\mathrm{b}}$ & $450.0 \pm 106.9^{\mathrm{a}, \mathrm{c}, \mathrm{d}}$ & $116.0 \pm 7.6^{\mathrm{b}}$ & $219.1 \pm 28.1^{b}$ & 0.041 & 0.009 & 0.353 \\
\hline $\begin{array}{c}\text { Cholesterol } \\
(\mathrm{mg} / \mathrm{dL})\end{array}$ & $51.1 \pm 4.4^{\mathrm{b}, \mathrm{d}}$ & $75.3 \pm 5.9^{\mathrm{a}}$ & $62.9 \pm 1.7^{\mathrm{d}}$ & $91.0 \pm 8.2^{\mathrm{a}, \mathrm{c}}$ & 0.027 & 0.0002 & 0.735 \\
\hline $\begin{array}{l}\text { Glucose } \\
(\mathrm{mg} / \mathrm{dL})\end{array}$ & $131.9 \pm 3.2^{\mathrm{b} . c}$ & $207.6 \pm 29.4^{\mathrm{a}}$ & $91.3 \pm 3.8^{\mathrm{c}}$ & $164.5 \pm 8.4^{\text {a.b }}$ & 0.0052 & $<0.0001$ & 0.926 \\
\hline
\end{tabular}

Data are mean \pm standard error mean (SEM) showing comparison between the different groups. a comparison with group CTL$\mathrm{CTL}_{\mathrm{Fl}}$, control offspring born from dams that were fed on control diet; $\mathbf{b}$ CTL-CAF $\mathrm{Fl}_{\mathrm{F}}$, cafeteria offspring born from dams that were fed on control diet; $\mathbf{c}$ CAF-CTL $\mathrm{Fl}_{\mathrm{F}}$, control offspring born from dams that were fed on a cafeteria diet; $\mathbf{d} \mathrm{CAF}-\mathrm{CAF} \mathrm{Fl}_{\mathrm{Fl}}$, cafeteria offspring born from dams that were fed on a cafeteria diet; $p$-values $(\mathrm{p}<0.05)$ by ANOVA followed by Post Hoc Tuckey's test. The number of animals analyzed was 5-7 rats per group from five different litters. 

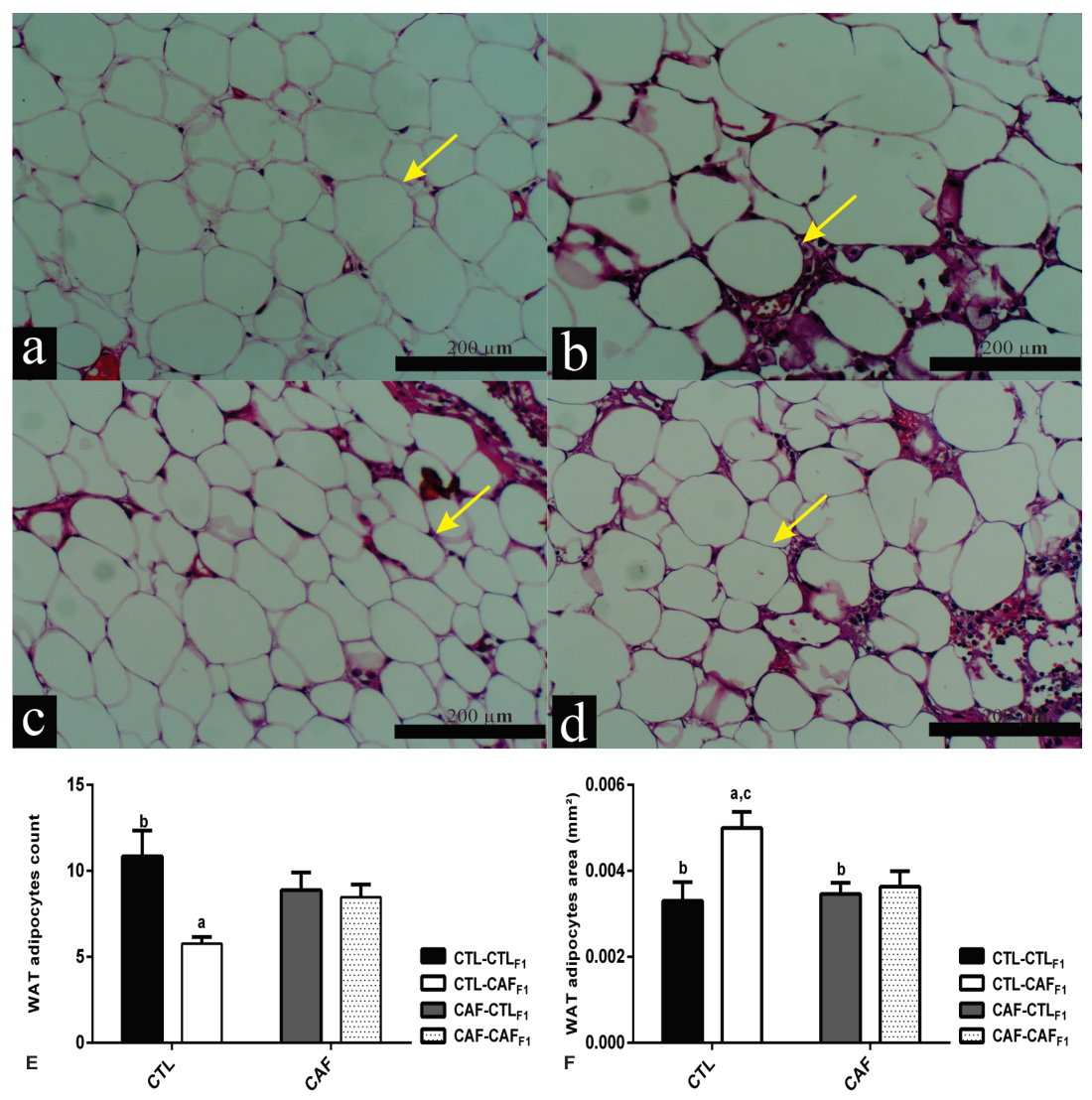

Figure 1 - Effects of exposure to CAF diet during pre and post weaning, alone or in combination, on histological aspects of the WAT depot of male adult F1 offspring at 100d of age. Representative histology of the WAT depot with H\&E staining (100X magnification); a-d; Scale bars: $200 \mu \mathrm{m}$. In all section were circled all adipocyte (field to field) and the area ( $\mathrm{mm} 2)$ was measured and the number of adipocytes also was counted for all cells (Figure $\mathrm{f}$ and e, respectively). Qualitative data are expressed as mean \pm standard error mean (SEM) showing comparison between the different groups. Adipocyte is indicated by yellow arrows. a comparison with group CTL-CTL ${ }^{\mathrm{F} 1}$, control offspring born from dams that were fed on control diet; $\mathrm{b} C \mathrm{CTL}-\mathrm{CAF}{ }^{\mathrm{F1}}$, cafeteria offspring born from dams that were fed on control diet; c CAF-CTL ${ }^{\mathrm{F} 1}$, control offspring born from dams that were fed on a cafeteria diet; $\mathrm{d} C A F-C A F^{F 1}$, cafeteria offspring born from dams that were fed on a cafeteria diet; $p$-values $(\mathrm{p}<0.05)$ by ANOVA followed by Post Hoc Tuckey's test. The number of animals analyzed was 5-7 rats per group from five different litters.

in relation than $\mathrm{CTL}-\mathrm{CTL}_{\mathrm{F} 1}$ and $\mathrm{CAF}-\mathrm{CTL}_{\mathrm{F} 1}$ groups. However, the degree of lipid accumulation was more evident in $\mathrm{CAF}-\mathrm{CAF}_{\mathrm{F} 1}$ group in which also was observed larger droplets in BAT compared to other experimental groups (Table II). However, the exposure of rats to the CAF diet, during the pre-or post-natal phases, resulted in fat deposition in the liver. Thus, in the CTL-CAF ${ }_{\mathrm{F} 1}$, CAF-CTL $\mathrm{F}_{\mathrm{F}}$ and $\mathrm{CAF}-\mathrm{CAF}_{\mathrm{F} 1}$ groups lipid accumulation was found in the liver (Figure 3a-d). According with Table II the CAF-CTL $\mathrm{F}_{1}$ group showed steatosis degree I and II, while CTL-CAF ${ }_{\mathrm{F} 1}$ and CAF-CAF ${ }_{\mathrm{F} 1}$ groups presented steatosis degree II and III in relation to other experimental groups. However, the degree of steatosis was more pronounced in adult $\mathrm{F} 1$ offspring of $\mathrm{CAF}-\mathrm{CAF}_{\mathrm{Fl}}$, which was the most affected group. Moreover, at $100 \mathrm{~d}$ of age the adult offspring $\mathrm{F} 1$ of CTL-CAF $\mathrm{F}_{1}, \mathrm{CAF}-\mathrm{CTL}_{\mathrm{F} 1}$ and 
TABLE II

Histological analysis of BAT lipid droplets profile and lipid hepatocyte infiltration of male offspring at age $100 \mathrm{~d}$.

\begin{tabular}{ccccccc}
\hline Variable & Categories & CTL-CTL $_{\mathrm{F} 1}$ & CTL-CAF $_{\mathrm{F} 1}$ & CAF-CTL $_{\mathrm{F} 1}$ & CAF-CAF $_{\mathrm{F} 1}$ & $\mathrm{p}-\mathrm{value}$ \\
\hline \multirow{2}{*}{ BAT fat } & Small & $5(100 \%)^{\mathrm{b}, \mathrm{d}}$ & $1(20 \%)^{\mathrm{a}, \mathrm{c}}$ & $6(100 \%)^{\mathrm{b}, \mathrm{d}}$ & $1(17 \%)^{\mathrm{a}, \mathrm{c}}$ & \\
vesicles & Medium & $0(0 \%)^{\mathrm{b}, \mathrm{d}}$ & $4(80 \%)^{\mathrm{a}, \mathrm{c}}$ & $0(0 \%)^{\mathrm{b}, \mathrm{d}}$ & $3(50 \%)^{\mathrm{a}, \mathrm{c}}$ & $<0.0001$ \\
& Large & $0(0 \%)^{\mathrm{d}}$ & $0(0 \%)^{\mathrm{d}}$ & $0(0 \%)^{\mathrm{d}}$ & $2(33 \%)^{\mathrm{a}, \mathrm{b}, \mathrm{c}}$ & \\
& Absent & $5(100 \%)^{\mathrm{b}, \mathrm{c}, \mathrm{d}}$ & $0(0 \%)^{\mathrm{a}}$ & $0(0 \%)^{\mathrm{a}}$ & $0(0 \%)^{\mathrm{a}}$ & \\
Hepatic & Degree I & $0(0 \%)^{\mathrm{c}}$ & $0(0 \%)^{\mathrm{c}}$ & $2(33 \%)^{\mathrm{a}, \mathrm{b}, \mathrm{d}}$ & $0(0 \%)^{\mathrm{c}}$ & $<0.0001$ \\
steatosis & Degree II & $0(0 \%)^{\mathrm{b}, \mathrm{c}}$ & $4(80 \%)^{\mathrm{a}, \mathrm{d}}$ & $4(67 \%)^{\mathrm{a}, \mathrm{d}}$ & $2(33 \%)^{\mathrm{b}, \mathrm{c}}$ & \\
& Degree III & $0(0 \%)^{\mathrm{d}}$ & $1(20 \%)^{\mathrm{d}}$ & $0(0 \%)^{\mathrm{d}}$ & $4(67 \%)^{\mathrm{a}, \mathrm{b}, \mathrm{c}}$ & \\
\hline
\end{tabular}

The degree of steatosis was graded ( 0 - 3), as follows: 0 , none to $5 \%$ of hepatocytes affected; $1,>5 \%$ to $30 \%$ affected; $2,>30 \%$ to $60 \%$ affected; and 3,>60\%. The size of fat droplets in the adipocyte cytoplasm was evaluated using the following criteria: small droplets $(+)$, media droplets $(++)$ and greater $(+++)$. Data are expressed in percentage $(\%)$ showing comparison between the different groups. a comparison with group CTL-CTL ${ }_{\mathrm{F} 1}$, control offspring born from dams that were fed on control diet; b CTL$\mathrm{CAF}_{\mathrm{F} 1}$, cafeteria offspring born from dams that were fed on control diet; $\mathbf{c}$ CAF-CTL $\mathrm{F}_{\mathrm{F}}$, control offspring born from dams that were fed on a cafeteria diet; $\mathbf{d} \mathrm{CAF}-\mathrm{CAF}_{\mathrm{Fl}}$, cafeteria offspring born from dams that were fed on a cafeteria diet. Monte Carlo test followed adjusted residuals test; ANOVA followed by Post Hoc Tuckey's test. $p$-value $(p<0.05)$. The number of animals analyzed was 5-7 rats per group from five different litters.

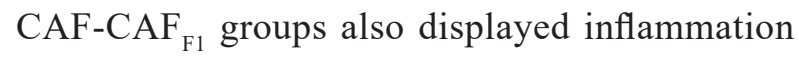
in liver (data not shown). Finally, the associations of biometric, metabolic plasma parameters and histological variables with maternal and offspring diet was made by PCA. According Figure 4, first principal component axis are represented offspring diet effects being negative score related to control diet while positive score are related to cafeteria diet. Thus, the CTL-CAF ${ }_{\mathrm{F} 1}$ group shows increase in body weight, adipocyte hypertrophy and higher deposition of fat in the liver, associated with high plasmatic levels of glucose; triglycerides and cholesterol. In contrast to CTL-CAF ${ }_{\mathrm{F} 1}$, the CAF$\mathrm{CAF}_{\mathrm{F} 1}$ group presented smaller body weight gain, WAT accumulation, plasmatic levels of glucose and triglycerides, although remained with higher lipid accumulation in BAT and liver.

\section{DISCUSSION}

An adequate nutritional environment, during pregnancy and lactation, is critical for optimal offspring development (Howie et al. 2009, Couvreur et al. 2011, Lee 2015). As such, the current epidemics of MS and T2D in adulthood may result from maternal obesogenic diet during these critical phases of development (Smith and Ryckman 2015). However, the mechanisms underpinning maternal obesity and how they interfere in the programming of obesity risk, in adult offspring, are not well defined (Akyol et al. 2012, Mucellini et al. 2014). Here, we evaluated whether post-weaning exposure to a CAF diet would result in the amplification of this phenotype in the adult F1 offspring of dams exposed to a life-time of CAF diet. In particular, the histological aspects of the WAT, BAT and liver tissues of these offspring were compared. Surprisingly, adult F1 offspring, derived from dams exposed to life-long CAF diet, including during pregnancy and lactation periods, did not present alterations in body weight, adipose tissue content, and parameter plasmatic evaluated. Our results are in agreement with those of other reports that have used an almost identical experimental design, and did not observe significant modifications in offspring (Akyol et al. 2012, Mucellini et al. 2014), or only a marginal effect in the exacerbation of the obesity phenotype, in adult F1 offspring (King et al. 2014). However, our findings contrast with data from other studies showing that offspring derived 

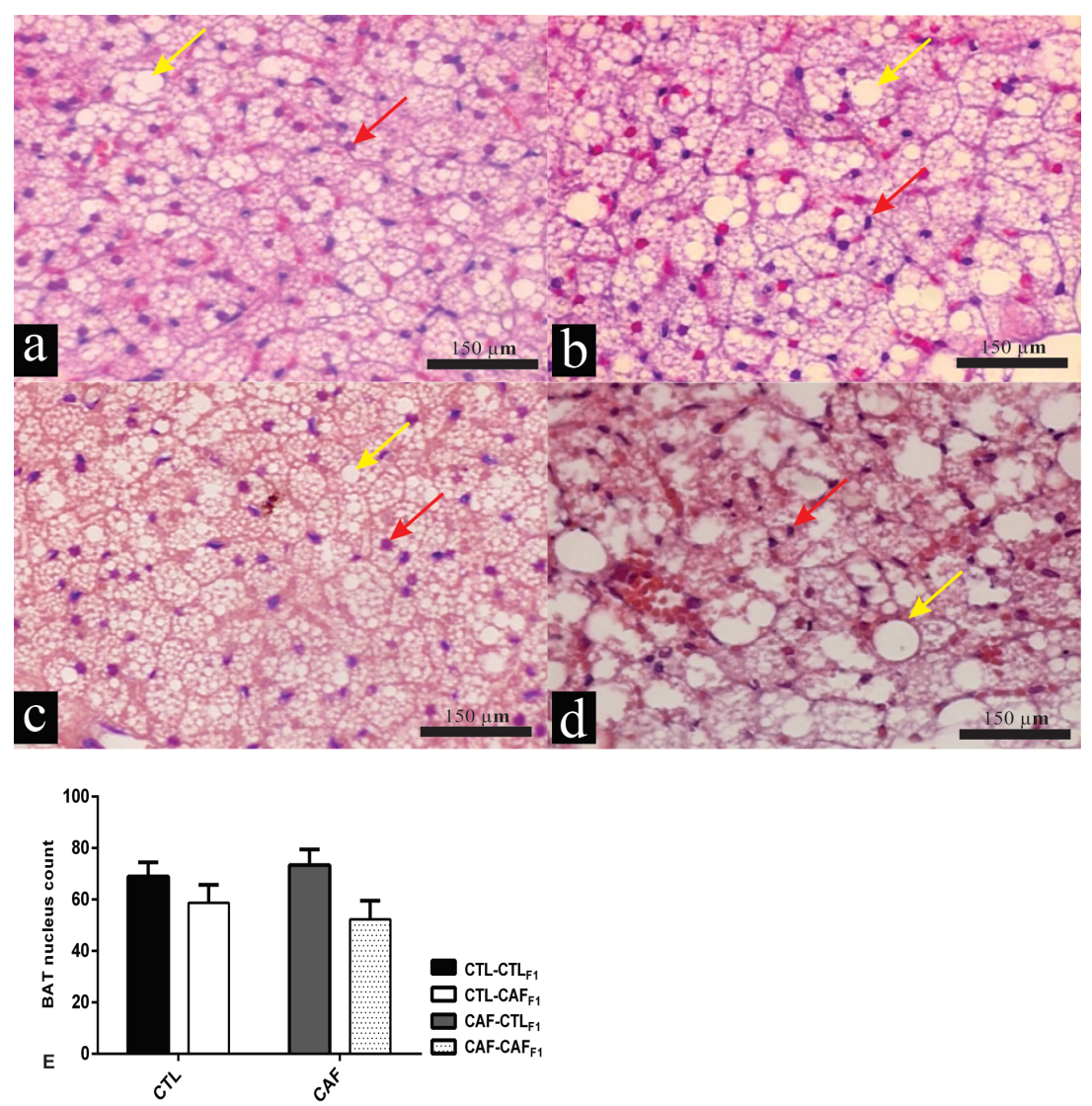

Figure 2 - Effect of exposure to CAF diet pre and post weaning, alone or in combination, on histological aspects of BAT from male adult F1 offspring at $100 \mathrm{~d}$ of age. Representative histology of BAT with H\&E staining (200X magnification); a-d; Scale bars: $150 \mu \mathrm{m}$. The profile of lipid droplets in the cytosol of adipocyte of BAT was qualitatively evaluated using next criterions; small lipid droplets $(+)$, mild lipid droplets $(++)$ and big lipid droplets $(+++)$. Quantitative analysis was performed by nuclei counts (e). Data are mean \pm standard error mean (SEM). Nuclei are indicated by red arrows and lipid droplets are indicated by yellow arrows. The number of animals analyzed was 5-7 rats per group from five different litters.

from dams submitted to maternal hypercaloric diets display obesity and metabolic abnormalities in adult life (Howie et al. 2009, Desai et al. 2015, Li et al. 2015). These contradictories results would be resultant of differences in the duration, timing of a nutritional intervention and profile of nutrients in diet, resulting in particular type of mechanism of programming (van de Heijning et al. 2017). In this sense, to evaluate the impact of CAF diet on maternal metabolism is important, once that, this state will determine the degree of metabolic programming on adult offspring. Using same CAF maternal diet in the present study, Mucellini et al. (2014) and Sagae et al.(2015) showed that the consume of CAF diet by female at long of life promotes rises in body weight associated with greater WAT accumulation; confirming the effectiveness of this diet to induce obesity in mothers. Moreover, Mucellini et al. (2014) also showed that maternal CAF diet does not alter glycemia or triglycerides levels, although induces hyperinsulinemia and the increase of total cholesterol in offspring in adult life. Important, according suggested by Howie et al. (2009) the 


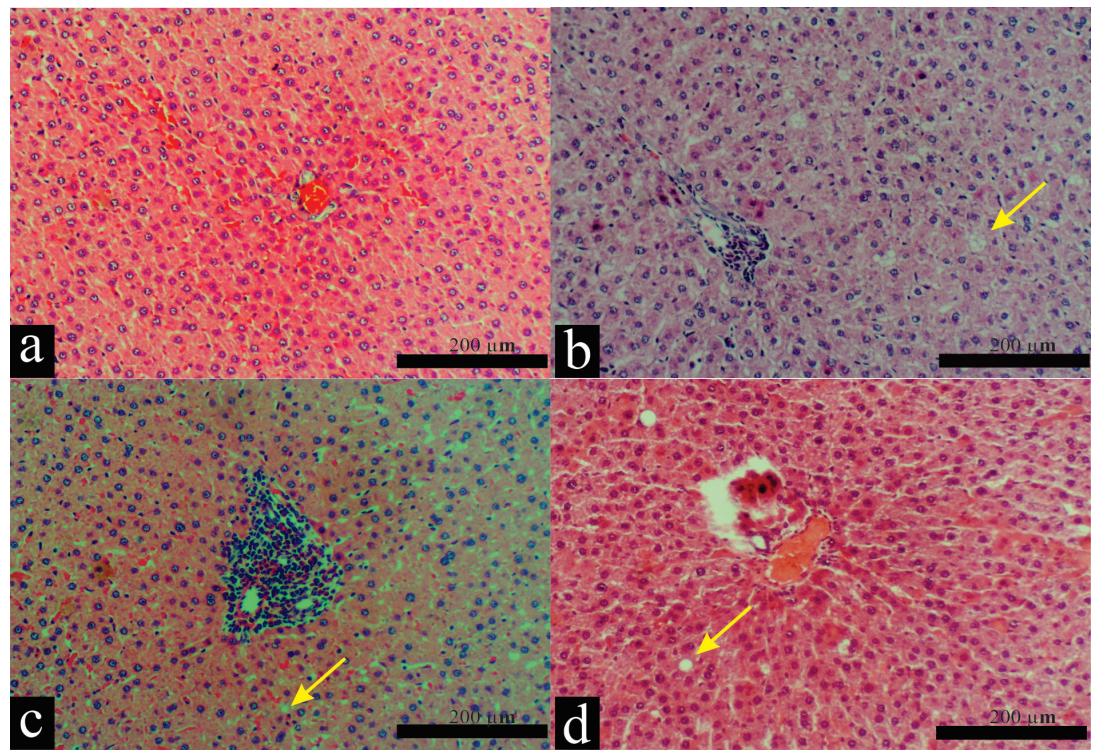

Figure 3 - Effect of exposure to CAF diet pre and post weaning, alone or in combination, on histological aspects of the liver of male adult F1 offspring at $100 \mathrm{~d}$ of age. Representative image of livers with H\&E staining (200X magnification); a-d; Scale bars: $150 \mu \mathrm{m}$. Qualitative histological analyses evaluated the profile of lipid infiltration in the hepatocyte cytosol. The degree of steatosis was evaluated according to Brunt (2001) (Table II). Lipid droplets are indicated by yellow arrows. The number of animals analyzed was 5-7 rats per group from five different litters.

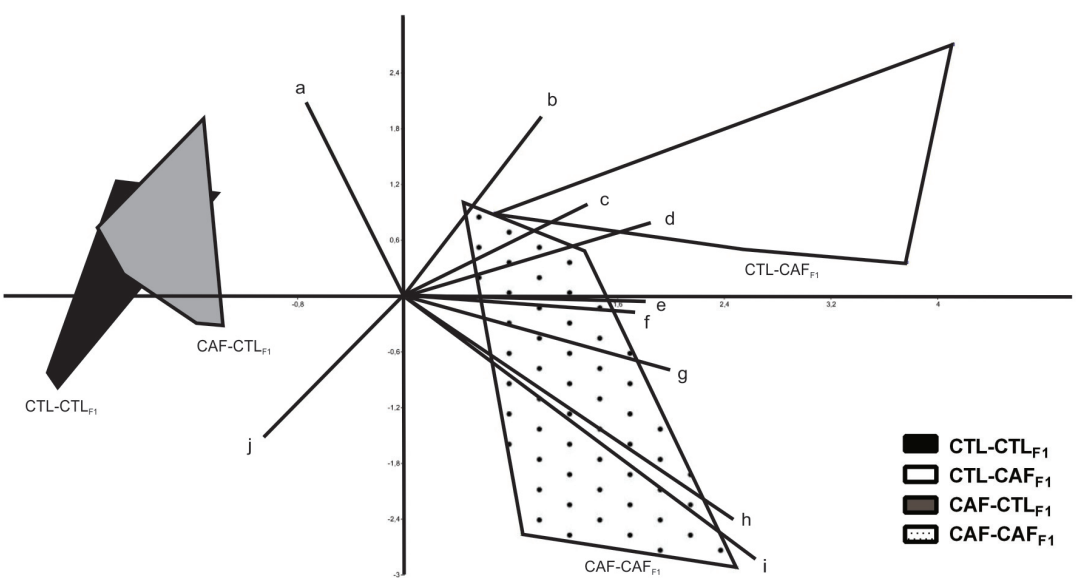

Figure 4 - Principal Component Analysis (PCA) Diagram. The letters in PCA represent a: Nucleus count in BAT; b: Adipocyte area in the WAT depot; c: Triglycerides; d: Body weight; e: Hepatic lipid accumulation; f: Glucose; g: Weight of WAT depot; $\mathbf{h}$ : Lipid droplets in BAT; i: Cholesterol; j: Adipocyte count in WAT depot. The number of animals analyzed was 5-7 rats per group from five different litters.

composition of the diet rather than maternal weight gain per se has an effect on offspring phenotype. It is well recognized that maternal diet exerts epigenetic effects, such as DNA methylation, determining which genes are expressed in offspring and how the metabolism of fetus adapt to environment at birth and in adulthood (Masuyama and Hiramatsu 2012, Dunford and Sangster 2017). 
Therefore, it is important to keep in mind that the degree of mismatch between the pre- and postnatal environments may be crucial to metabolic programming. Thus, the initial adaptive physiological changes in fetal and pre-natal periods, necessary to guarantee survival, may be maladaptive in later life (Fernandez-Twinn and Ozanne 2006, Gluckman et al. 2008). Nevertheless, our findings show that, independently of maternal diet, postweaning exposure to the CAF diet promotes obesity, hyperglycemia, and dyslipidemia in adult F1 offspring. Mucellini et al. (2014), using the same experimental design that we used, including the same CAF diet, analyzed the offspring immediately after weaning (21 days of age) and no found difference in the body weight of animals whose mothers were fed with CAF diet or standard diet; an effect also observed at 30 days of age. However, at 30 days of age, offspring fed with $\mathrm{CAF}$ diet showed higher visceral fat, without maternal diet influence. In rats, intense adipogenesis occurs during the last week of pregnancy and also during lactation; showing that these periods are particularly sensitive to the developmental programming of adiposity (Lukaszewski et al. 2013). The expansion of WAT is morphologically characterized by increases in the sizes of individual adipose cells (hypertrophy) or augmented adipocyte numbers (hyperplasia) (Cinti 2012, Bezpalko et al. 2015). Any imbalance in this mechanism favors chronic inflammatory processes in this tissue, which are the hallmark of obesity and metabolic disorders (Rosen and Spiegelman 2006). Interestingly, we found the worst morphological profile in the WAT of adult F1 offspring exposed to the CAF diet just during post weaning; these alterations were characterized by adipocyte hypertrophy and a reduction in adipocyte numbers. Furthermore, the combined effect of maternal CAF diet with the post-weaning CAF diet (CAF-CAF ${ }_{\mathrm{F} 1}$ group) prevented morphological changes in the WAT, thus in this group the size and the number of adipocytes were similar to that of the
$\mathrm{CTL}_{-\mathrm{CTL}_{\mathrm{F} 1}}$ group. These results show that maternal CAF diet did not exacerbate the obesity phenotype induced by exposure to the CAF diet during post weaning. In fact, the maternal obesogenic diet appears to protect the WAT in adult F1 offspring. The reduction in body weight and in WAT depot and histological aspects of this tissue in CAF$\mathrm{CAF}_{\mathrm{F} 1}$ rats may be due to improvement in glucose and triglycerides. Similarly, offspring of high fatfed mothers are adaptively more suited to a postnatal high fat diet (Howie et al 2009). The protective effect of maternal overnutrition on adult F1 offspring also has been previously reported (Fernandez-Twinn and Ozanne 2006, FerezouViala et al. 2007) and, as suggested by Gluckman et al. (2008) these events involve predictive adaptive response mechanisms (Gluckman et al. 2008). Similarly, Couvreur et al. (2011) showed that the degree of obesity in offspring born to obese dams was not exacerbated by exposure at diet highly palatability post-weaning. In according with these authors, this protective effect of maternal obesogenic diet on offspring alters hypothalamic leptin signaling, programming the metabolism of adult offspring to minimize the degree of dietinduced obesity (Couvreur et al. 2011). However, as described below, the impact of early life exposure to maternal CAF diet on morphological tissue aspects, in adult $\mathrm{F} 1$ offspring, appears be tissuespecific. The development of BAT starts during pregnancy, with intense recruitment occurring during the lactation and post-weaning phases (Giralt et al. 1990, Ferezou-Viala et al. 2007). Thus, nutritional insults during these critical periods can reduce thermogenic activity in the BAT, thereby suppressing energy expenditure and, ultimately, promoting obesity in adulthood (Cannon and Nedergaard 2004). BAT adipocytes contain numerous smaller lipid vesicles, dispersed throughout the cytosol, giving a multilocular morphological aspect to this depot (Cinti 2012). The profile of lipid droplets in the cytosol of BAT 
adipocytes reflects the degree of thermogenic activity and, indirectly, represents increased sympathetic flux driven to the tissue (Tupone et al. 2014). Maternal overnutrition induces functional and morphologic changes in the BAT of adult offspring, leading to fat deposition, inflammation, and alterations in the activity of sympathetic nerves (Lukaszewski et al. 2013). However, our results show that the maternal exposure to CAF diet did not affect morphologic aspects in the BAT of adult F1 offspring that consumed a normal diet at post weaning. These results contrast with those obtained by others, where maternal CAF diet was found to promote significant alterations in BAT in adult offspring that were not reversed by the exposure to a normal post-weaning diet (Barbato et al. 2015, Dinh et al. 2015). As expected, we observed that post-weaning exposure to a CAF diet induces lipid overload in the BAT of adult F1 offspring, an effect that is independent of the maternal diet profile. Thus, in contrast to observations in the WAT depot, the maternal CAF diet did not protect adult offspring that were also exposed to a life-long CAF diet. In a recent review, BAT was reported to be vulnerable to nutritional insults, especially those occurring during the pre- and post-natal periods of life (Bayol et al. 2007, Barbato et al. 2015). Considering that WAT and BAT depots have different embryological origins, and employ different pathways of proliferation and differentiation during pregnancy and lactation, it is probable that the windows of vulnerability to nutritional insults are depotspecific, resulting in different morphological adjustments when animals are fed on a CAF diet, later on in life.

Taken together, we can draw two important conclusions from these results. Firstly, the maternal CAF diet alone, does not alter blood plasmatic parameters (glucose, triglycerides and cholesterol), WAT content, as well as, no modified histological aspects of the WAT and BAT in adult offspring, at $100 \mathrm{~d}$ of age, suggesting that solely maternal CAF diet, does not programming these tissues. Secondly, while the exposure to maternal CAF diet, associated with post-weaning CAF exposure, protects WAT in adult $\mathrm{F} 1$ offspring, CAF diet exposure during the post-weaning period has a deleterious effect on the BAT, independently of the maternal diet. Considering that, at $100 \mathrm{~d}$ of age, the rats are young adults; it is possible that the deleterious effects of programming in these tissues may occur at a more advanced age. This hypothesis is supported reports that the effects of maternal programs are found in adult offspring at 140-155d of age (Shankar et al. 2008, Howie et al. 2009). In addition, the impact of maternal diet on adult offspring is sex dependent, as females appear to be more sensitive to the effect of maternal diet programming, when compared with males (Onyekwere et al. 2015).

In contrast to the observations in WAT and BAT, maternal exposure alone to a CAF diet exerts programming effects on the liver in adult F1 offspring, at $100 \mathrm{~d}$ of age. The abnormal lipid deposition in hepatocytes results in hepatic steatosis, a pathological state related to liver abnormalities, such as the nonalcoholic fatty liver disease (NAFLD). NAFLD is the most common chronic liver disease present in obese subjects, and is closely associated with manifestations of MS (Linnemann et al.2014, Calvo et al.2015). Although hepatic steatosis is a key histological feature in this process, variations in morphological aspects have been observed; thus hepatocellular steatosis is usually classified as either macrovesicular or microvesicular (Kleiner et al. 2005). Our data confirm the impact of the maternal CAF diet on the liver programming effect in adult F1 offspring, as previously demonstrated by others (Bouane et al. 2010, Podrini et al. 2013; Kleiner et al. 2005, Bringhenti et al. 2015). The maternal obesogenic diet can induce lipid deposition in the fetal liver before birth, a crucial event in metabolic disease during adult life (Ingvorsen et al. 2015). Recently, using an identical experimental design to that 
of our study, a programming effect of maternal high fat diet was demonstrated on the liver of adult offspring (Ito et al. 2016); in this study, the plasma metabolic parameters, body weight, and WAT content were not programmed by maternal obesogenic diet, corroborating our findings. Interestingly, according to histological analysis in our study, the consumption of CAF diet pre $\left(\mathrm{CAF}-\mathrm{CTL}_{\mathrm{F} 1}\right)$ and pos-weaning $\left(\mathrm{CTL}-\mathrm{CAF}_{\mathrm{F} 1}\right)$ alone results in higher lipid infiltration in liver. However, this effect is markedly exaggerated when the dams and offspring $\left(\mathrm{CAF}-\mathrm{CAF}_{\mathrm{F} 1}\right)$ have been exposed to CAF diet throughout life. As previously demonstrated by Bruce et al. (2009) and Pruis et al. (2014), the higher hepatic lipid accumulation in offspring could be attributed to up-regulation of de novo fatty acid synthesis, failure to up-regulate mitochondrial beta oxidation and fatty acid export. Animal models indicate that programmed effects, in particular hepatic steatosis, are highly irreversible after weaning. For example, long-term consumption of a normal chow diet after weaning may not be effective in normalizing offspring susceptibility to NAFLD induced by maternal high fat diet (Li et al. 2015). In contrast, Bringhenti et al. (2011) reported that introducing fish oil to a post weaning diet can reverse maternal low protein diet induced hepatic steatosis in offspring. It probable that epigenetic events induced by maternal overnutrition leads to altered DNA methylation pattern of the offspring during their development and influencing their later health (Pruis et al. 2014).

Finally, in our study, we used a method denominated Principal Component Analysis (PCA), a classical multivariate exploratory tool that highlights common variation between variables, allowing conclusions to be made about the possible biological meaning of associations between them, without pre-establishing cause-effect relationships (Figure 4). In conclusion, the post-weaning exposure to the $\mathrm{CAF}$ diet alone $\left(\mathrm{CTL}-\mathrm{CAF}_{\mathrm{F} 1}\right)$, induces evident characteristics of MS in adult F1 offspring, such as an increase in body weight and weight of liver and WAT; associated with adipocyte hypertrophy in WAT and deposition of fat in the liver and BAT, which probably contributes to hyperglycemia and dyslipidemia. Interestingly, the pre and post weaning CAF diet exposure throughout of life protects offspring from the deleterious effects provoked by exposure to CAF diet alone post weaning. Thus, adult F1 offspring, in the CAF-CAF $\mathrm{F}_{\mathrm{F} 1}$ group (representing the combined effect of maternal obesogenic CAF and post weaning CAF diet) are less predisposed to body weight gain and to WAT accumulation, improved glycemia and triglyceride levels, in relation to exposure alone to the CAF diet during the post-weaning phase. This protector effect of maternal CAF diet did not was observed in BAT and liver, suggesting that the impact of the maternal obesogenic diet on male offspring adult rats is tissuespecific. Our study emphasizes the importance of the diet throughout the mother's life for establishing tissue-specific effects in the offspring in response to an obesogenic diet in adulthood.

\section{ACKNOWLEDGMENTS}

This study is part of MSc. thesis of Carolyne D.S. Santos. We are grateful to $\mathrm{PhD}$ Antonio Carlos Boschero for performed corrections and Nicola Conran for editing English. This research received no specific grant from any funding agency in the public, commercial, or not-for-profit sectors. None of the authors declared a conflict of interest. Author contributions: Balbo; S.L. and Grassiolli; S. designed the study; Santos; C.D.S.; Negretti, F. and Sagae; S.C. collected the data; Guimarães, A.T.B. analyzed the data; Balbo; S.L.; Grassiolli; S. and Santos; C.D.S. wrote the paper and performed corrections.

\section{REFERENCES}

AKYOL A, MCMULLEN S AND LANGLEY-EVANS SC. 2012. Glucose intolerance associated with early-life 
exposure to maternal cafeteria feeding is dependent upon post-weaning diet. Br J Nutr 107: 964-978.

BARBATO LD, TATULLI G, VEGLIANTE R, CAMATA SM, BERNARDINI S, CIROLO MR AND AQUILANO K. 2015. Dietary fat overload reprograms brown fat mitochondria. Front Physiol 6: 1-12.

BARKER DJ. 2004. The developmental origins of adult disease. J Am Coll Nutr 23(Supl 6): 588S-595S.

BAYOL AS, FARRINGTON SJ AND STICKLAND NC. 2007. A maternal 'junk food' in pregnancy and lactation promotes an exacerbated taste for 'junk food' and greater propensity for obesity in rat offspring. Br J Nutr 98: 843-851.

BEZPALKO L, GAVRILYUK O AND ZAYACHKIVSKA O. 2015. Inflammatory response in visceral fat tissue and liver is prenatally programmed: experimental research. $\mathrm{J}$ Physiol Pharmacol 66: 57-64.

BOUANE S, MERZOUK H, BENKALFAT NB, SOULIMAN N, MERZOUK SA, GUSTI J, TESSIER C AND NARCI M. 2010. Hepatic and very low-density lipoprotein fatty acids in obese offspring of overfed dams. Metab Clin Exp 59: 1701-1709.

BRINGHENTI I, SCHULTZ A, RACHID T, BOMFIM MA, MANDARIM-DE-LACERDA CA AND AGUILA MB. 2011. An early fish oil enriched diet reverses biochemical, liver and adipose tissue alterations in male offspring from maternal protein restriction in mice. J Nutr Biochem 22: 1099-1014.

BRINGHENTI I, ORNELLAS F, MARTINS MA, MANDARIM-DE LACERDA CA AND AGUILA MB. 2015. Early hepatic insult in the offspring of obese maternal mice. Nutr Res 35: 136-145.

BRUCE KD ET AL. 2009. Maternal high fat feeding primes steatohepatitis in adult mice offspring, involving mitochondrial dysfunction and altered lipogenesis gene expression. Hepatol 50(6): 1796-808.

BRUNT EM. 2001. Nonalcoholic steatohepatitis: definition and pathology. Semin Liver Dis 21: 3-16.

CALVO NETAL. 2015. Liver fat deposition and mitochondrial dysfunction in morbid obesity: An approach combining metabolomics with liver imaging and histology. World J Gastroenterol 21(24): 7529-7544.

CANNON B AND NEDERGAARD JAN. 2004. Brown Adipose Tissue: Function and Physiological Significance. Physiol Rev 84: 277-359.

CINTI S. 2012. The adipose organ. Dis Model Mech 73: 9-15. COUVREUR O, FEREZOU J, GRIPOIS D, SEROIGNE C, CRÉPIN D, AUBOURG A, VACHER CM AND TAOUIS M. 2011. Unexpected long-term protection of adult offspring born to high-fat fed dams against obesity induced by a sucrose-rich diet. PLoS ONE 6(3): e18043.

DANIEL ZC, AKYOL A, MCMULLEN S AND LANGLEYEVANS SC. 2014. Exposure of neonatal rats to maternal cafeteria feeding during suckling alters hepatic gene expression and DNA methylation in the insulin signalling pathway. Genes Nutr 9: 1-10.

DESAI M, JELLYMAN JK AND ROSS MG. 2015. Epigenomics Gestational programming and risk of metabolic syndrome. In J Obes 39: 633-641.

DINH CH, SZABO A, YU Y, CAMER D, ZHANG Q, WANG H AND HUANG XF. 2015. Bardoxolone Methyl Prevents Fat Deposition and Inflammation in Brown Adipose Tissue and Enhances Sympathetic Activity in Mice Fed a HighFat Diet. Nutrients 7: 4705-4723.

DUNFORD AR AND SANGSTER JM. 2017. Maternal and paternal periconceptional nutrition as an indicator of offspring metabolic syndrome risk in later life trough epigenetic imprinting: A systematic review. Diabetes Metabol Syndrom 10: 1871- 4021.

FÉRÉZOU-VIALA J ET AL. 2007. Long-term consequences of maternal high-fat feeding on hypothalamic leptin sensitivity and diet-induced obesity in the offspring. Am J Physiol Regul Integr Comp Physiol 293: R1056-R1062.

FERNANDEZ-TWINN DS AND OZANNE SE. 2006. Mechanisms by which poor early growth programs type2 diabetes, obesity and the metabolic syndrome. Physiol Behav 88: 234-243.

GIRALT M, MARTIN I, IGLESIAS R, VINAS O, VILLARROYA F AND MAMPEL T. 1990. Ontogeny and perinatal modulation of gene expression in rat brown adipose tissue to environmental temperature at birth. Eur J Biochem 193: 297-302.

GLUCKMAN PD, HANSON MA, BEEDLE AS AND SPENCER HG. 2008. Predictive adaptive responses in perspective. Trends Endocrinol Metab 19:109-110.

GOULARTE F, FERREIRA MBC AND SANVITTO GL. 2012. Effects of food pattern change and physical exercise on cafeteria diet-induced obesity in female rats. Br J Nutr 108: $1511-1518$.

HAIR JR JF, BLACK WC, BABIN BJ, ANDERSON RE AND TATHAM RL. 2009. Análise multivariada de dados. $6^{\text {a }}$ ed., Porto Alegre, Bookman, 688 p.

HAMMER Ø, HARPER DAT AND RYAN PD. 2001. Paleontological statistics software package for education and data analysis. Palaeontol Electronica 4: 9-18.

HOWIE GJ, SLOBODA DM, KAMAL T AND VICKERS MH. 2009. Maternal nutritional history predicts obesity in adult offspring independent of postnatal diet. J Physiol 4: 905-915.

INGVORSEN C, BRIX S, OZANNE SE AND HELLGREN LI. 2015. The effect of maternal inflammation on foetal programming of metabolic disease. Acta Physiol 2: 440-449.

ITO J, NAKAGAWA K, KATO S, MIYAZAWA T, KIMURA F AND MIYAZAWA T. 2016. The combination of maternal and offspring high-fat diets causes marked oxidative stress and development of metabolic syndrome in mouse offspring. Life Sciences 151: 70-75. 
JACOBS S, TEIXEIRA DS, GUILHERME C, CLAUDIO FK, ARANDA BCC AND REIS AR. 2014. Physiology \& Behavior The impact of maternal consumption of cafeteria diet on reproductive function in the offspring. Physiol Behav 129: 280-286.

KAYSER BD, GORAN MI AND BOURET SG. 2015. Perinatal Overnutrition Exacerbates Adipose Tissue Inflammation Caused by High-Fat Feeding in C57BL / 6J Mice. PlosOne 10: 1-15.

KLEINER DE ET AL. 2005. Design and validation of a histological scoring system for nonalcoholic fatty liver disease. Hepatol 41: 1313-1321.

KING V, NORMAN JE, SECKL JR, DRAKE AJ. 2014. Postweaning diet determines metabolic risk in mice exposed to overnutrition in early life. Reprod Biol Endocrinol 12: 1-7.

LEE HS. 2015. Impact of Maternal Diet on the Epigenome during In Utero Life and the Developmental Programming of Diseases in Childhood and Adulthood.

Nutrients 7: 9492-9507.

LI M, REYNOLDS CM, SEGOVIA SA, GRAY C AND VICKERS MH. 2015. Developmental Programming of Nonalcoholic Fatty Liver Disease: The Effect of Early Life Nutrition on Susceptibility and Disease Severity in Later Life. Bio Med Res Int 1-12.

LI M, SLOBODA DM AND VICKERS MH. 2011. Maternal Obesity and Developmental Programming of Metabolic Disorders in Offspring: Evidence from Animal Models. Exp Diabetes Res 2011: 1-9.

LINNEMANNAK, BAAN MAND DAVIS DB. 2014. Pancreatic $\beta$-Cell Proliferation in Obesity. Adv Nutr 5(3): 278-288.

LUKASZEWSKI MA, EBERLÉ D, VIEAU D AND BRETON C. 2013. Nutritional manipulations in the perinatal period program adipose tissue in offspring. Am J Physiol Endocrinol Metab 305: E1195-E1207.

MASUYAMA H AND HIRAMATSU Y. 2012. Effects of a high-fat diet exposure in utero on the metabolic syndromelike phenomenon in mouse offspring through epigenetic changes in adipocytokine gene expression. Endocrinol 153: 2823-2830.

MUCELLINI AB GOULARTE F, CARLA A, ARAUJO D, NOSCHANG C AND BENETTI S. 2014. Effects of exposure to a cafeteria diet during gestation and after weaning on the metabolism and body weight of adult male offspring in rats. Br J Nutr 111: 1499-1506.

ONYEKWERE CA, OGBERA AO, SAMAILA AA AND BOLOGUM BO. 2015. Nonalcoholic fatty liver disease: synopsis of current developments. Niger J Clin Pract 18: 703-712.

PODRINI C ET AL. 2013. High-fat feeding rapidly induces obesity and lipid derangements in C57BL $/ 6 \mathrm{~N}$ mice. Mamm Genome 24: 240-251.

PRUIS MG, LENDVAI A, BLOKS VW, ZWIER MV, BALLER JF, DE BRUIN A, GROEN AK AND PIOSCH T. 2014.
Maternal western diet primes non-alcoholic fatty liver disease in adult mouse offspring. Acta Physiol 210: 215-227.

RAMÍREZ-LÓPEZ MT, VÁZQUEZ BERRIOS M, ARCO GONZÁLEZ R, BLANCO VELILLA RN, DECARA DEL OLMO J, SUÁREZ PÉREZ J, RODRÍGUEZ DE FONSECA F AND GÓMEZ DE HERAS R. 2015. The role of maternal diet in metabolic and behavioural programming: review of biologic mechanisms involved. Nutr Hospital 32: 2433-2445.

REEVES PG. 1997. Components of the AIN-93 Diets as Improvements in the AIN-76A Diet. In: Symposium: Animal Diets for Nutr Toxicol Res, p. 838-841.

ROSEN ED AND SPIEGELMAN BM. 2006. Adipocytes as regulators of energy balance and glucose homeostasis. Nature 444: 847-853.

SAGAE SC, GOBO CG, PAZ ED, MENEGOTTO JB, FRANCI CF AND BALBO SL. 2015. Blockade of AT1 receptor of Angiotensin II reduces the number of antral follicles in female rats with obesity induces by cafeteria diet. Rev Bras Ginecol Obstet 37: 302-307.

SAMPEY BP, VANHOOSE AM, WINFIELD HM, FREEMERMANN AJ, MIEHLBAUER MJ, FUEGER PT, NEWGARD CB AND MAKOWSKI L. 2011. Cafeteria Diet Is a Robust Model of Human Metabolic Syndrome With Liver and Adipose Inflammation: Comparison to High-Fat Diet. Obes 19: 1107-1117.

SEDAGHAT K, ZAHEDIASL S AND GHASEMI A. 2015. Intrauterine programming. Iran J Basic Med Sci 18: 212-220.

SHANKAR K, HARRELL A, LIU X, GILCHRIST JM, RONIS MJJ AND BADGER TM. 2008. Maternal obesity at conception programs obesity in the offspring. Am J Physiol Regul Integr Comp Physiol 294: R528-R538.

SMITH CJ AND RYCKMAN KK. 2015. Epigenetic and developmental influences on the risk of obesity, diabetes and metabolic syndrome. Diabetes Metab Syndr Obes 8: 295-302.

TAMASHIRO KLK, TERRILLION CE, HYUN J, KOENIG JI AND MORAN TH. 2009. Prenatal Stress or High-Fat Diet Increases Susceptibility to Diet-Induced Obesity in Rat Offspring. Diabetes 58: 1116-1125.

TUPONE D, MADDEN CJ AND MORRISON SF. 2014. Autonomic regulation of brown adipose tissue thermogenesis in health and disease: Potential clinical applications for altering BAT thermogenesis. Front Neurosci 8: 1-14.

VAN DE HEIJNING BJM, OOSTING A, KEGLER D AND VAN DER BEEK EM. 2017. An increased dietary supply of medium-chain fatty acids during early weaning in rodents prevents excessive fat accumulation in adulthood. Nutrients 9: 631- 646.

WHITE CL, PURPERA MN AND MORRISON CD. 2009. Maternal obesity is necessary for programming effect of high-fat diet on offspring. Am J Physiol Regul Integr Comp Physiol 296: 1464-1472. 